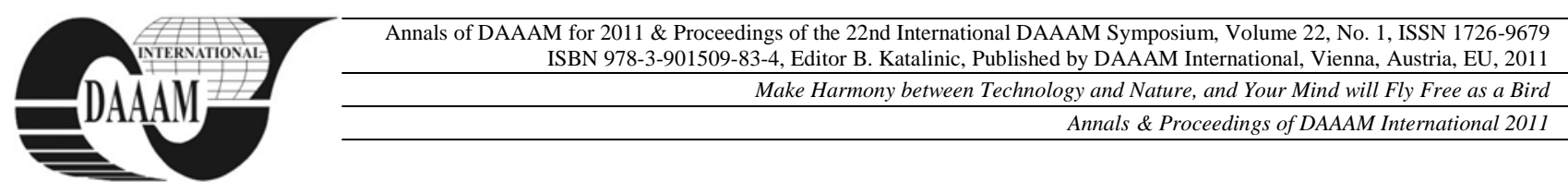

\title{
ANALYSIS OF ELASTIC RECOVERY PHENOMENA IN BENDING PROCESS
}

\author{
GUSEL, L[eo]
}

Abstract: Bending belongs to the most widely applied types of sheet metal forming and has been investigated thoroughly. Although several improvements have been made in material formability and tool steels, many researchers are still active to describe accurately the phenomena occurring the process. In the paper, the influence of the effective strain to elastic recovery of sheet metal specimens was analysed. Experiments have been done to find out the amount of elastic recovery of bent metal sheets. Different specimens were used for the experimental analysis of elastic recovery ratio and angle. Regression analysis methods were used for obtaining of mathematical models.

Keywords: metal forming, bending process, elastic recovery, regression analysis

\section{INTRODUCTION}

Bending is the uniform straining of material around a straight axis and is used commonly in various sheet metal industrial products. Since all materials have a finite modulus of elasticity, plastic deformation is followed by some elastic recovery when the load is removed. Elastic recovery occurs not only in flat sheets or plate, but also in bars, rods, etc., and is one of the key factors to influence the quality of bent sheet metal parts. There are many parameters which have influence on elastic recovery, one of them is strain hardening. Among them, the elastic recovery, that occurs after the pressure of the forming tools has been removed and results from the change in strain produced by elastic recovery when the load is released, remains the fundamental problem in the practice of the sheet metal forming processes, especially bending.[1]

As a matter of fact, it causes deviations from the desired final shape and doesn't permit the conformity of the product shape with the design specifications. Elastic recovery is dependent on the elastic and plastic deformation behaviour of material, thickness and width of the sheet, tooling geometry.[2]

The strain hardening during metal forming has also a great influence on the elastic recovery ratio. Accurate prediction of the springback of metal sheets after a forming operation is of vital importance for the design of tools in the industry.

\section{ELASTIC RECOVERY IN BENDING}

A purely elastically bent sheet will return to its original configuration upon removal of the bending moment. After partially plastic bending, permanent deformation and residual stresses remain after unloading [3]. For the calculation of elastic recovery in the praxis, ratio $\mathrm{K}$ and angle $\Delta \alpha$ have to be determined. The expression

$$
K=\frac{r_{1}+0,5 \cdot s}{r_{2}+0,5 \cdot s}
$$

and expression

$$
K=\frac{\varphi_{2}}{\varphi_{1}}
$$

are called springback ratio [1]. If $\mathrm{K}$ is known from experiment, the springback angle can be determined by:

$$
\Delta \alpha=\varphi_{1}-\varphi_{2}=\left(\frac{1}{K}-1\right) \cdot \varphi_{2}
$$

where $\mathrm{s}$ is the thickness of the bending material [1].

\section{EXPERIMENTAL WORK}

The aim of the experimental work was to determine the influence of the effective strain reached by cold drawing to springback ratio and springback angle of steel X6Cr13.

Steel was deformed by cold drawing from initial diameter $\mathrm{D}_{0}=20 \mathrm{~mm}$ to six different diameters (Table 1 ). The drawing speed was $15 \mathrm{~m} / \mathrm{min}$ and the angle of drawing die was $\delta=28^{\circ}$.

\begin{tabular}{cccc}
\hline $\begin{array}{c}\text { Spec. } \\
\text { Nr. }\end{array}$ & $D_{0}[\mathrm{~mm}]$ & $D_{\mathrm{k}}[\mathrm{mm}]$ & $\begin{array}{c}\text { Effect. } \\
\text { strain } \varepsilon_{\mathrm{e}}\end{array}$ \\
\hline I & 20 & 19 & 0,102 \\
II & 20 & 18 & 0,211 \\
III & 20 & 17 & 0,325 \\
IV & 20 & 16 & 0,446 \\
V & 20 & 15 & 0,575 \\
VI & 20 & 14 & 0,713 \\
0 & 20 & 20 & $/$ \\
\hline
\end{tabular}

Tab. 1. Cold drawing of steel bars

From each of six different cold drawn bars, experimental specimens (thin strips) of dimensions $100 \mathrm{~mm}$ $\mathrm{x} 14 \mathrm{~mm} \times 1 \mathrm{~mm}$ and $100 \mathrm{~mm} \times 14 \mathrm{~mm} \times 1,5 \mathrm{~mm}$ were made. These specimens were used for the experimental determination of springback ratio and springback angle and were bent in a special bending tool. Radius of the bending punch (r) was $6 \mathrm{~mm}$.

During the bending, the angle of the specimen profile and inner radius of the bent specimen were measured. Many experiments and measuring were done to assure accuracy. By insertion of measured results in the equation (1) it is possible to calculate the springback ratio for differently deformed specimens. 


\section{RESULTS AND DISCUSION}

Results of experiments are presented in a form of diagrams on Fig. 1 and Fig. 2. The diagram on Fig. 1 shows the influence of the effective strain on springback angle $\Delta \alpha$. Instead of specimen number, the $\mathrm{x}$-axis shows the effective strain of specimens reached by cold drawing. As we can see, the lowest value of springback angle is reached when effective strain is zero (non-deformed specimen). With increasing effective strain $\varepsilon_{\mathrm{e}}$ springback angle $\Delta \alpha$ also increases reaching the highest value at $\varepsilon_{\mathrm{e}}=0,71$ (specimen VI).

At this point springback angle is $28 \%$ higher then springback angle of non-deformed specimen. Figure 2 shows the influence of effective strain $\varepsilon_{\mathrm{e}}$ on springback ratio $\mathrm{K}$. At more deformed specimens the springback ratio is lower. Specimen VI has 5\% lower springback ratio as non-deformed specimen (specimen 0). It can also be noticed that the value of $\mathrm{K}$ at the same effective strain is higher for thicker specimen $(\mathrm{s}=1,5 \mathrm{~mm})$.

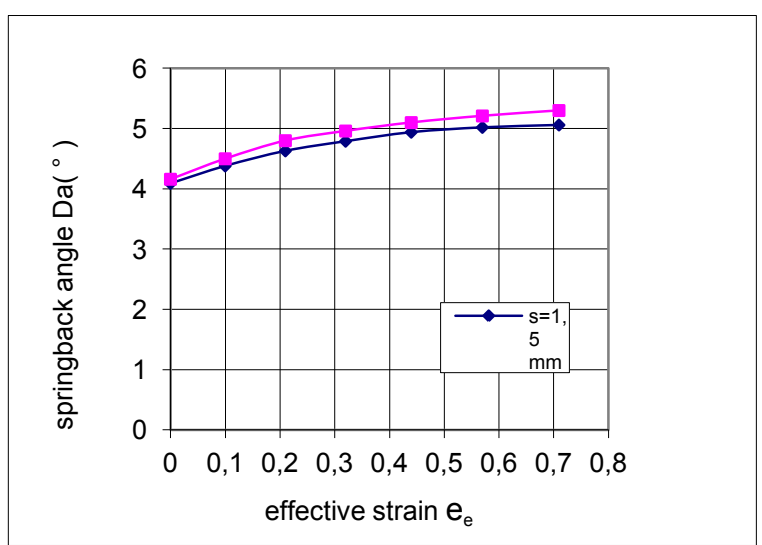

Fig. 1. Impact of effective strain on springback angle of the specimens

Results of the experimental work can be presented in equations by using statistical analysis methods, for example regression analysis [5, 6].

By using regression analysis the influence of parameters on springback ratio and springback angle can be represented in a form of equations:

For $\mathrm{s}=1,5 \mathrm{~mm}$ :

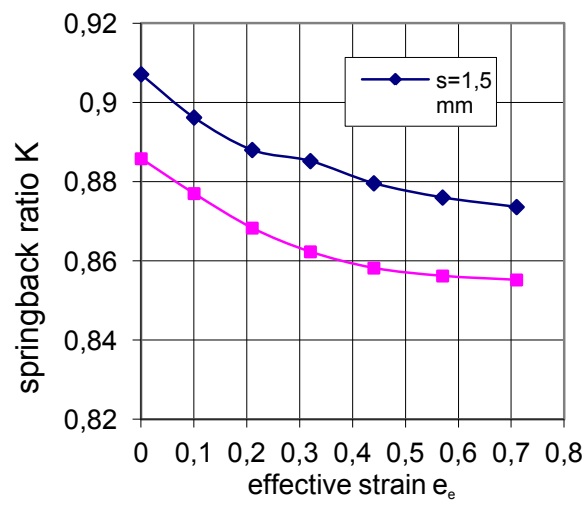

Fig. 2. Impact of effective strain on springback ratio of the specimens

$$
\begin{aligned}
& \begin{array}{l}
\Delta \alpha=4,1026+2,8763 \cdot \varepsilon_{e}-2,1605 \cdot \varepsilon_{e}^{2} \\
K e=0,9057-0,0884 \cdot \varepsilon_{e}+0,0616 \cdot \varepsilon_{e}^{2}
\end{array} \\
& \text { For s }=1 \mathrm{~mm}:
\end{aligned}
$$

$$
\begin{gathered}
\Delta \alpha=4,1876+3,1746 \cdot \varepsilon e-2,2907 \cdot \varepsilon_{e}^{2} \\
K e=0,8857-0,0973 \cdot \varepsilon_{e}+0,0766 \cdot \varepsilon_{e}^{2}
\end{gathered}
$$

By using equations (4) to (7) it is possible to determine springback ratio and springback angle for every value of effective strain inside experimental area (from 0 to 0,71 ).

The difference between measured and calculated values is less then 3\%. Results are accurate for the values of $r$ and $\mathrm{s}$ as noticed on the diagrams (Fig. 1 and Fig. 2).

\section{CONCLUSION}

Our experimental work and results that we calculated have confirmed the influence of the effective strain to springback ratio and springback angle. With higher effective strain springback angle also increases while springback ratio decreases. Springback ratio depends also on thickness of the sheet to be bend and on proportion $\mathrm{r} / \mathrm{s}$. The results indicate higher springback ratio and lower springback angle for thicker material. Conclusions of the research can be used for the design of tools for bending of $\mathrm{X} 6 \mathrm{Cr} 13$ steel and other materials with similar mechanical characteristics. In the future, further experiments will be done to obtain impact of other mechanical and chemical characteristics on springback ratio and springback angle of bent sheet specimens.

\section{REFERENCES}

Andersson, A. (2005).Numerical and experimental evaluation of springback in a front side member, Journal of Materials Processing Technology 169, 352 356

Anžel, I.;Gusel, L. (2005). Metal forming - Praktikum, Faculty for Mechanical Engineering Maribor, Maribor

Barnes, W. J. (2004). Statistical Analysis for Engineer and Scientists - s computer based approach, The University of Texas at Austin, McGraw Hill, New York

Chu, E.; Zhang, I.; Wang, S.; Maker B. (2002). Validation of springback predictability with experimental measurements and die compensation for automotive panels, Numisheet, Jeju Island, Korea

Chelu, G.; Ghiban, N.; Saban, R.; Ghiban, B.; Serban, N. (2008) Strain rate and material state influence on the deformation Resistance of some tool steels. DAAAM International Scientific Book, 219-228, Vienna

Lange, K. (1992). Umformtechnik - Handbuch für Industrie und Wissenschaft, Band 1, 2 und 3, Berlin 